\title{
Impactos da Adoção de Infraestruturas de Nuvem no Desenvolvimento de Pesquisas Acadêmicas
}

\author{
Maicon Ança dos Santos $^{1}$, Gerson Geraldo H. Cavalheiro ${ }^{1}$ \\ ${ }^{1}$ Programa de Pós-Graduação em Computação \\ Centro de Desenvolvimento Tecnológico - Universidade Federal de Pelotas (UFPel) \\ Campus Porto - Rua Gomes Carneiro, 1 - 96010-610 - Pelotas - RS - Brazil \\ \{madsantos, gerson. cavalheiro\}@inf.ufpel.br
}

\begin{abstract}
Resumo. Este trabalho apresenta uma proposta de estudo que tem como objetivo definir estratégias para racionalizar a adoção de nuvens computacionais para apoio à pesquisa acadêmica, determinando os modelos de custo necessários para implantação de uma solução, atendendo a uma comunidade federada de Instituições de Ensino e Pesquisa (IEP). O enfoque será dado considerando a realidade do Estado do Rio Grande do Sul, com um olhar sobre as vocações de pesquisa de suas instituições e a realidade de financiamentos de projetos. Dentre as contribuições esperadas para este trabalho, está a modelagem de diferentes configurações de nuvem, públicas, privadas ou híbridas, que possam atender as demandas do conjunto de IEPs do estado.
\end{abstract}

\section{Introdução}

O modelo de computação em nuvem se apresenta como uma infraestrutura de suporte à execução sob demanda para aplicações que vão desde simples portais web a grandes fluxos de trabalho científicos. Neste ambiente computacional, recursos podem ser rapidamente provisionados e liberados com o mínimo esforço de gerenciamento ou interação com o provedor de serviços [Mell and Grance 2011].

O setor de educação tem se beneficiado das tecnologias disponibilizadas pela implementação e adoção de serviços de nuvem para os usuários finais [Singh et al. 2020]. Nos ambientes de pesquisa acadêmicos, nuvens para computação de alto desempenho (HPC) estão se tornando uma alternativa aos clusters dedicados para execução de aplicações científicas [Netto et al. 2018], pois oferecem ao usuário a possibilidade de ajustar, rapidamente, seus recursos de computação por meio de mecanismos oferecidos pelos próprios provedores de serviços de nuvem.

Um dos aspectos que promovem a adoção de nuvens por centros de pesquisa ou instituições comerciais é o financeiro. No caso de nuvens públicas, observa-se um menor custo total de propriedade (TCO) e uma maior flexibilidade em termos de recursos e acordos de nível de serviço (SLAs). Isso permite, à instituição, foco nos negócios, ignorando problemas relacionados ao gerenciamento da infraestrutura [Aceto et al. 2013]. Para soluções de nuvens privadas, a centralização dos recursos tem efeito similar, concentrando os custos de propriedade e de gestão em um setor especializado da instituição, mas distribuindo entre os demais setores, seu uso.

O objetivo deste trabalho é racionalizar, em relação aos custos financeiros, a adoção de nuvens para apoio à pesquisa acadêmica, determinando os custos envolvidos 
para implantação de uma solução, atendendo a uma comunidade federada de instituições de ensino e pesquisa. O enfoque será dado considerando a realidade do Estado do Rio Grande do Sul, com um olhar sobre as vocações de pesquisa de suas instituições e realidade de financiamento de projetos. Serão abordadas alternativas com ambientes de nuvens públicas, privadas e híbridas, identificando vantagens e desvantagens da adoção de cada uma e os respectivos impactos financeiros.

\section{Contexto da Pesquisa}

As pesquisas acadêmicas possuem um grande papel na sociedade. Por meio delas, é possível o desenvolvimento de novas tecnologias que auxiliam na descoberta de soluções para problemas do cotidiano, contribuindo para uma melhor qualidade de vida. A implantação e a manutenção das infraestruturas de pesquisa requer investimentos consideráveis. A ideia da colaboração entre pesquisadores e grupos de pesquisa se mostra atrativa por abrir a possibilidade da diluição destes custos e/ou da potencialização dos resultados.

Neste sentido, a computação em nuvem surge como uma alternativa para a escassez de recursos computacionais, bem como para racionalização no uso de recursos financeiros. No setor produtivo, seu uso é apresentado como uma solução real, como atestam diversos trabalhos encontrados na literatura. Mas seu potencial também já é explorado por instituições acadêmicas.

\section{Metodologia e Oportunidade de Pesquisa}

De posse das necessidades de cada projeto de pesquisa, associado aos modelos de custo para implantação de infraestruturas de nuvem, é possível traçar estratégias que justifiquem a adoção de diferentes cenários, em diferentes modelos de implantação, apresentando os aspectos positivos e negativos de cada solução.

Por fim, delimitando o estudo de caso, será caracterizado o cenário mais adequado às características das pesquisas desenvolvidas no Estado do Rio Grande do Sul, juntamente com as necessidades de um ciclo de investimentos que contemple implantação e manutenção da infraestrutura de nuvem computacional para apoio às Instituições de Ensino e Pesquisa.

\section{References}

Aceto, G., Botta, A., de Donato, W., and Pescapè, A. (2013). Cloud monitoring: A survey. Computer Networks, 57(9):2093-2115.

Mell, P. and Grance, T. (2011). The NIST definition of cloud computing. Technical report, National Institute of Standards and Technology, Gaithersburg, MD.

Netto, M. A. S., Calheiros, R. N., Rodrigues, E. R., Cunha, R. L. F., and Buyya, R. (2018). HPC Cloud for Scientific and Business Applications: Taxonomy, Vision, and Research Challenges. ACM Computing Surveys, 51(1):1-29. arXiv: 1710.08731.

Singh, J., Mansotra, V., Mir, S. A., and Parveen, S. (2020). Cloud feasibility and adoption strategy for the INDIAN school education system. Education and Information Technologies. 